\title{
Research of College Students’ Social Cognitive Abilities Based on Social Practice Education
}

\author{
Zhichun Li \\ Liaoning Police Academy \\ No.260, Yingping Road, Dalian, 116036 China \\ lnpolice@126.com
}

\begin{abstract}
Social Cognition Education (SCE) of college student has spawned a proliferation of studies in the past two decades. Social cognition level (SCL) of college student is deemed pivotal to the pursuit of both personal empowerment and the economic development of a society. Most of the contemporary interpretations of social cognition are inextricably intertwined with lifelong learning. In this paper, we investigated the personal social cognition level (knowledge, attitudes and behavior) of a sample of students of public security college using the personal characteristics. Second, we examined peer influences on the level of social cognition of college students. Finally, we examined how college students' social knowledge and attitudes correlated with their social behavior. The study found that through police practice, students can improve their practical ability, ability for application of knowledge, and ability to innovate and enhance their sense of police responsibility and police professional identity so as to inspire their spiritual power to learn.
\end{abstract}

Keywords- social cognition; SCE; relation of SCE; police practice

\section{INTRODUCTION}

Chinese university always pays great importance to social cognition education of college students, highlighting and educating students through practice. And Chinese government has issued a series of documents, showing their great attention to social practice and at the meantime providing guidance for social cognition education, thus, has created a huge challenge for higher education [1].

The purpose of social cognition education is improving social cognition level, including improving behavior knowledge, and developing self-efficacy, which are conducive to individual profession capacity. The social cognition education of college students as not limited to the dissemination of cognition-related information but also fostering the reciprocal determinism, environmental factors, behavioral capability, self-regulation reinforcement, learning through observation necessary to take action to improve the level of social cognition.

Much has been written over the years about the relationship, uniqueness and overlap between social cognition education, for college student, social cognition promotion and other concepts, such as social literacy, primary cognition care, community development and mobilization, and the role of empowerment. Attempting to describe these various relationships is not easy; findings and consensus will not fall neatly into place like the pieces of a jigsaw puzzle. Furthermore, discussion around these concepts can be intense since the professional affiliation associated with them is often strong and entrenched.

This study had three purposes. First, we investigated the personal social cognition (social knowledge, attitudes and behavior) of a sample of police college students. Second, we examined education and peer influences on the level of social cognition of college students. Finally, we examined how students' social practice of Police College, cognition consciousness, survival skills, social cognition affection, as well as social practice conducts code.

\section{Social Cognitive Theory of Police College STUDENTS}

\section{A. Theoretical Framework}

This study had three purposes. First, we investigated the personal social cognition (social behavioral capability, Learning through observation) of a sample of college students. Second, we examined education and peer influences on the level of social cognition of police college students. Finally, we examined how students' social practice of Police College, cognition consciousness, survival skills, social cognition affection, as well as social practice conducts code. [2]

The theoretical construct predominantly used when studying social cognition and education practice is systems theory. Systems theory is self-reflexive and is a cybernetic inputthroughput-output-feedback model. The present research used social cognition theory, based in systems theory, to understand the social cognition practices of police college students. We also examined the data through the lens of social practices theory.

The four stages in the police practices model, as developed by Literature [3], explain how college students make social decisions and develop social behaviors. The stages are inputs, throughputs, outputs, and feedback loop (see Figure 1). For this study, we only examined the inputs and throughputs sections of the model and added the environmental influences of family and school (see Figure 1). The outputs and feedback sections of the model were beyond the scope of this study. To measure outputs and feedback requires longitudinal data, which the researcher did not gather for this study. 


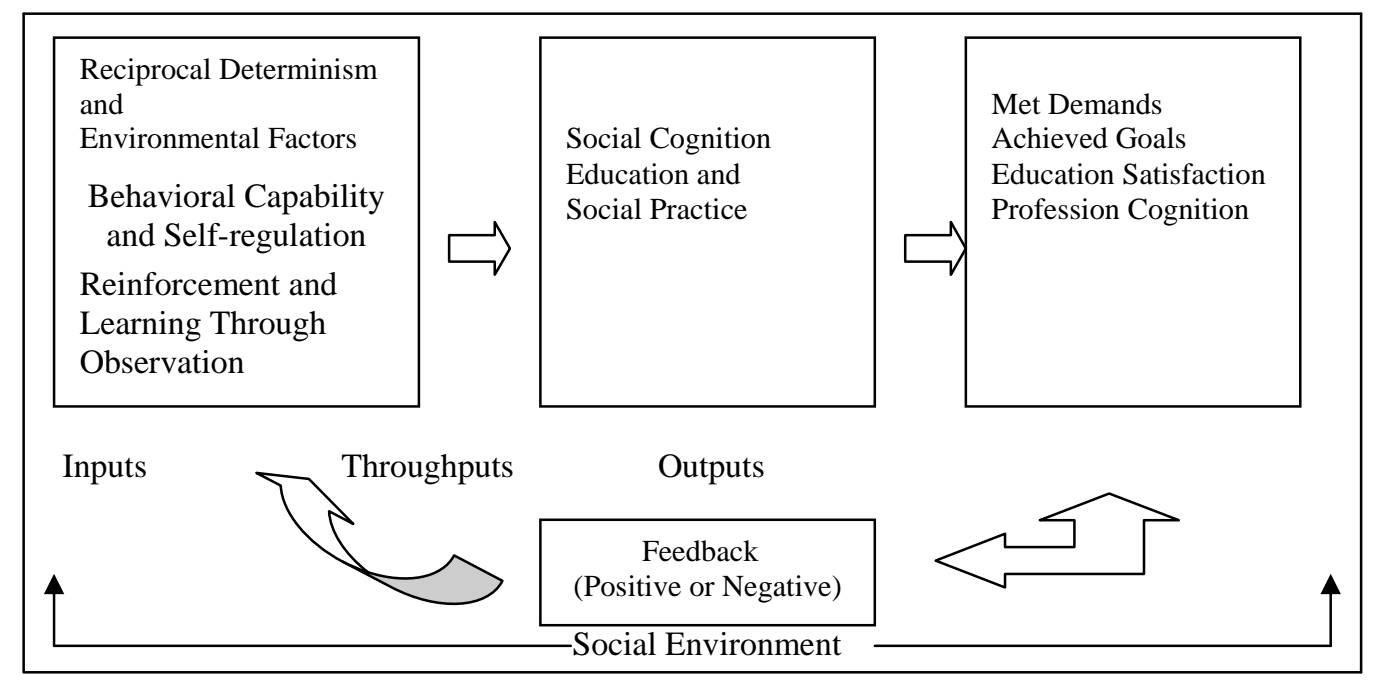

FIGUREI. SOCIAL COGNITION MODEL

Social learning theory helps explain the environmental influences police college students have had over the years shaping them into who they are today. The attitudes and behaviors college students have about social cognition come from their home environment (see Figure 1). As students learn over the years through social interaction, they begin to understand and form their values, knowledge, and attitudes about social. Family, friends, community, nation, school, church and media all shape college students' knowledge and attitudes over time [4].

This study combines social learning theory and family cognition influences theory in a way that considers environmental influences that shape where a person currently is in regards to their knowledge, attitudes, and personal characteristics (see Figure 2).

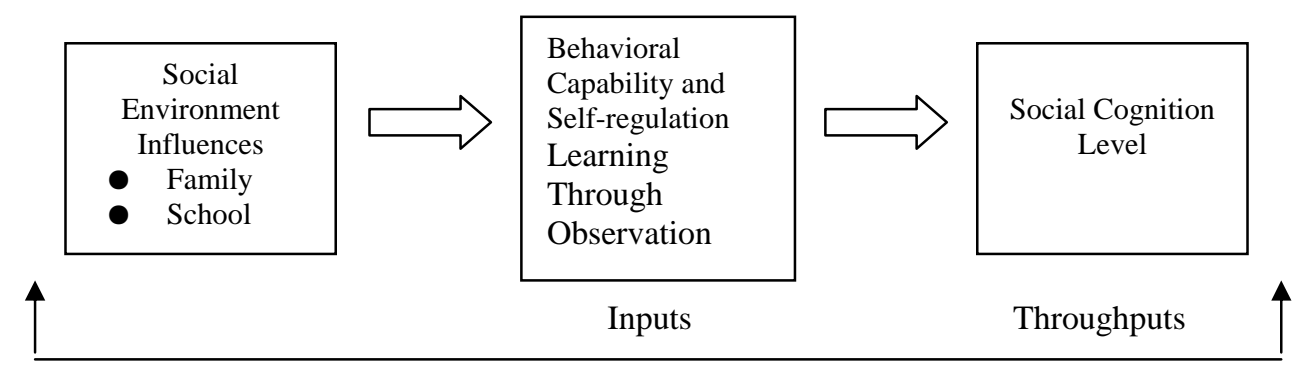

Environment

FIGURE II. SCIAL COGNITION LEVEL BASED ON ENVIRONMENT

The focus of this study is the social knowledge, attitudes, and behaviors of college students along with the two key environmental influences of family and school that help shape students current status. The environmental influences of family and school focused on for this study because of the great influence they have on police college students' social knowledge, attitudes, and behaviors. Family tend to have a greater influence on students at a younger age while peer influence increases as the student becomes older and especially after becoming a police college student. The addition of these environmental influences to our understanding of college students' social knowledge, attitudes, and behavior is a major contribution of this study [5].

\section{B. Social Cognition Education and Social Cognition Promotion for Police College Students}

Despite its widespread use in literature, the traditional way of conceptualizing social cognition solely as either social retrieval skills or social cognition capacity is deemed inadequate to encompass the visions of education in the 21st century. Social cognition is a process of turning social knowledge, attitudes and behavior into meaning, understanding, and new ideas. This process would require students to understand the rationale behind using knowledge as well as actually knowing the exact procedures of conducting the information search. Students need to 'knowhow', but more importantly, they must first 'know-why'. 
Hence, being social cognition would contribute towards personal empowerment through the learning to learn. The emerging digital culture coupled with the trends in economic globalization and the quest for a knowledge-based society have been creating tremendous momentum to drive the development and infusion of social cognition in education and all spheres of political, economical and social life of the twenty-first century.

In this regard, we argue that social cognition should be framed in a way to empower students to develop in them the capacity for lifelong learning, and to assume greater autonomy and social responsibilities over their learning. The notion of social cognition should be broadened to embrace a wider spectrum of learning outcomes manifested in different dimensions of learning in the information age.

\section{Relationship Between Major Social Cognition Concepts}

Social cognition promotion of police college students is concerned with improving social cognition by seeking to influence lifestyles, education and learning model and, above all, environments (which are not limited to the physical environment but encompass as well the cultural and socioeconomic circumstances that substantially determine social cognition status).

Social cognition promotion has its roots in many different disciplines. Over time it incorporated several previously separate components, one of which was social cognition education. Some authorities hold the view that social cognition promotion comprises three overlapping components: social cognition education, social cognition practice and risk evaluation of social cognition. Social cognition education, for example, includes educational efforts to influence lifestyles that guard against risk as well as efforts to encourage participation in social practice [6].

Social cognition education, according to this formula, focuses on building individuals' capacities through educational, motivational, skill-building and consciousnessraising techniques. Police practice of college students provides the environmental supports that will encourage and enhance behavior change. By influencing both these intrinsic and extrinsic factors, meaningful and sustained change in the social cognition of individuals and communities can be realized [7]. This relationship is illustrated in greater detail in Figure 3.

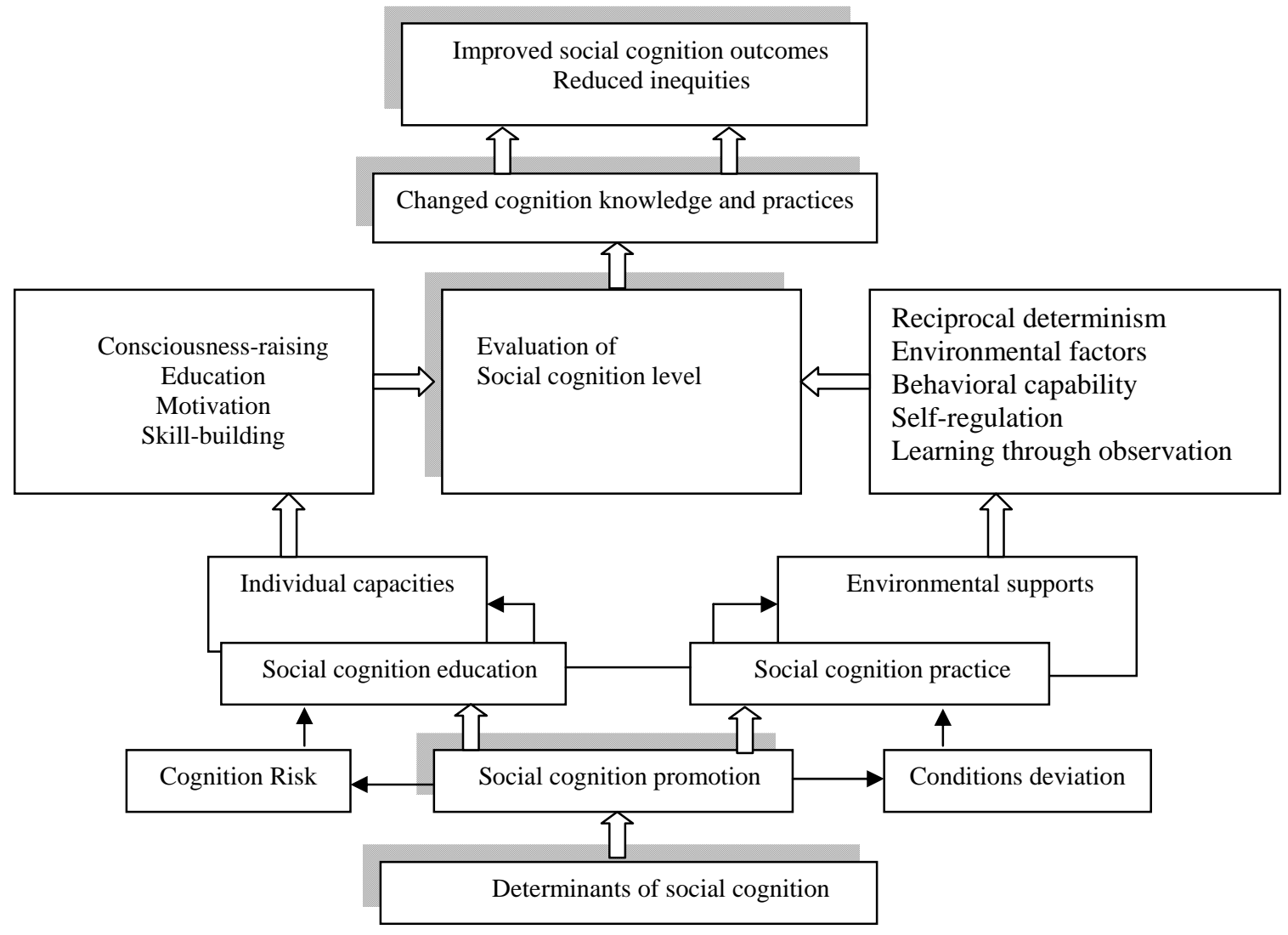

FIGURE III. RELATIONSHIP BETWEEN MAJOR SOCIAL COGNITION CONCEPTS 


\section{SOCIAL COGNITION EDUCATION BASED ON POLICE PRACTICE}

\section{A. Practical Values of Police Practice Education}

Police colleges always pay great importance to police practice education, highlighting and educating students through practice. And there are several practical values for doing police practice education.

First, to carry out police practice education is a strategic move to improve the quality of police higher education. Through police practice, students can apply the knowledge they gain from book into police practice, enhance their understanding and use of what they have learnt, so that they can test, develop and innovate during practice. This can in turn enhance the people police responsibility, innovative spirit, and police practical abilities of the students, which undoubtedly is an effective measure to improve police higher education.

Second, to carry out police practice education is the only way for preparatory police to grow. We know a combination of education and police practice is an important content of Chinese education policy, as well as the only way for young intellectuals to grow. For public security college, knowing only the book cannot be considered as a real people police. In order to acquire complete knowledge of police, students should take part in police practice, know the work of police, make application of police theories, develop police skills, and create values. Only in this way can students acquire comprehensive development and become the one the police department really need [8].

Third, to carry out police practice education is the fundamental way to optimize the quality of police talent structure. Police practice education plays an irreplaceable role in developing students' police responsibility to serve the country and the people, as well as developing innovative spirit and problem-solving ability. Through police practice, students can improve their practical ability, ability for application of knowledge, and ability to innovate and enhance their sense of police responsibility and police professional identity so as to inspire their spiritual power to learn.

\section{B. The Main Ways of Police Practice Education of Police College Students}

Police practice education is carried out in a variety of ways, including police surveys, producing activities, voluntary service, public service activities, technological inventions, work-study, and other social activities. Generally, there are three basic ways.

The first is observation police education. It mainly refers to the observation of police practice. Through observation, students compare the police practical results with that before the police practice and reach correct conclusions, so as to form and strengthen the right social cognition. It includes social and police surveys, visits and other forms of police activities.
Students mainly live in campus, so they basically lack social practice in social life. Through social and police surveys, visits and other observation education, college students can directly contact the police work. Through police investigations students can improve their ability to analyze and solve police problems independently, and enhance their sense of police responsibility.

The second is participation police education. It refers to Students' participation in police practice activities directly. Through personal experience, students not only observers, but also participates in all kinds of police activities. In this way, university students can not only confirm and gain the correct ideological theory in police practice, but also create and develop them [9].

The third is tempered police education. It mainly refers to the participation in hard police practice and exercise so as to temper students' will. Concerned with the increasing police competition and pressure, and most students are from onechild family who lack hard temper and psychological fortitude, it is necessary to carry out hard practice and exercise. Through military training, survival training, work-study,

\section{The Basic Requirement of The Social Practice Education for College Students}

In order to improve the actual effect of police practice education for police college students, we need to actively explore and promote the combination of police practice with professional learning, which reflects the basic requirement of social practice education for college students.

First, combine theory learning with police practice. On one hand, a police theory is the guide to police practice, and on the other hand, police practice is the essential way of examining, consolidating and developing the police theory. Police college students need to participate in police practice, and combine their theoretical knowledge with police practice. Only in this way can they examine the theory, consolidate the theory and develop the police theory, as well as promote the police practice and finally achieve the unity of knowing and doing [10].

Second, combine school practice and outside-school practice. School practice mainly refers to the practice of science experiments, teaching practice, student work, public service activities, etc. The teachers and students are its main part; campus life is its main platform. Outside-school practice mainly refers to the off-campus teaching practice. Outsideschool practice is an extension of school education and teaching activities. The persistence in combining school practice and outside-school practice is a prerequisite for the success of the practice education for police college students. Through the effective combination of school practice and outschool practice, both the teachers and students can directly contact with the police work, strengthen links with the police work, and accept the police department inspection of the 
outcomes of school education. So that we can find the problems of school education and then get feedback and do required adjustment, which is conducive in promoting the reform of police higher education [11].

\section{CONCLUSION}

Despite the limitations described earlier, the present study has made some unique contributions to the social cognition of college students. This study attempted to expand the understanding of the environmental influences of police college students on the social cognition of college students by combining social learning theory and education practice theory, as depicted in the Model of the Study (Figure 1-3). In addition, this study examined the differences in social cognition (Behavioral capability, Self-regulation, Learning through observation) based police college students.

Combine personal development with public security development. Adhere to combining personal development with public security development is not only the basic requirements of police practice education for police college students, but also the fundamental purpose of guiding students to participate in police practice. Through guiding the police college students to go deep into the society and participate in practice, we can improve their analytical and problem-solving skills, so that they can enhance their abilities and be educated in the police practice. And at the same time, we can guide the police college students to make full use of their Intelligence and ability in police practice and contribute to the country's modernization. In this process, what's more, we can cultivate their consciousness of serving the society and people, and enhance their sense of historical mission and police responsibility. Only by promoting personal development of Police College students combined with public security development in police practice, can we truly train the students to become the pillars of the country.

\section{ACKNOWLEDGMENT}

The authors are grateful for the support given by 2013 national education scientific planning project of China (Grant No. FIB120443). We also thank reviewers for insightful and helpful suggestions.

\section{REFERENCES}

[1] Bandura, A., Human Agency in social cognitive theory. American Psychologist, 1989, 44, pp.1175-1184.

[2] Bandura A, Social Learning Theory, Prentice Hall.

[3] Jinqi Li, Ping He, A Research on Police Higher Education's Contribution to Social Management in China, Proceedings of 2013 World Congress on Education, 2013, pp.194-199.

[4] Bandura, A, Social foundations of thought and action: A social cognitive theory. Englewood Cliffs, NJ: Prentice-Hall, 1986.

[5] Anderson, E. S., Winnett, R. A., \& Wojcik, J. R., Self-regulation, selfefficacy, outcome expectations, and social support: Social cognitive theory and nutrition behavior. Annals of Behavioral Medicine, 2007, 34, 304-312.

[6] Bandura, A., Social cognitive theory: An agentic perspective. Annual Review of Psychology,2001, 52, 1-26.

[7] Taymoori, P, Rhodes RE, Berry, Application of a social cognitive model in explaining physical activity in Lranian female adolescents. Health Education Res, 2010,25,pp.257-267.

[8] Mehta P, Sharma M, Bemard A, Social cognition theory as a predictor of dietary behavior and leisure time physical activity behavior in middleaged Asian Indian women residing in United States. Int Q Community Health Educ, 2010, 30, pp.257-269.

[9] Sallis JF, Grossman RM, Pinski RB, Patterson TL, Nader PR, The development of scales to measure social support for diet and exercise behaviors. Prev Med, 1987, 16, pp.825-836.

[10] Zhengwei Zhu and Qunying Xiao, International Social Management Evaluation System: Theory and Application Foreground, Journal of Public Management, 2006, 54, pp.23-27 (Chinese).

[11] He Ping, On the Construction of Social Management Rxtenics, Liaoning Police Academy, 2013, No.3, pp.1-5 (Chinese). 